\title{
Allocution de Son Exc. Mgr Georges Cabana
}

\section{Georges Cabana}

Volume 33, 1966

URI : https://id.erudit.org/iderudit/1007315ar

DOI : https://doi.org/10.7202/1007315ar

Aller au sommaire du numéro

Éditeur(s)

Les Éditions Historia Ecclesiæ Catholicæ Canadensis Inc.

ISSN

0318-6172 (imprimé)

1927-7067 (numérique)

Découvrir la revue

Citer ce document

Cabana, G. (1966). Allocution de Son Exc. Mgr Georges Cabana. Sessions d'étude - Société canadienne d'histoire de l'Église catholique, 33, 11-12.

https://doi.org/10.7202/1007315ar

Tous droits réservés @ Les Éditions Historia Ecclesiæ Catholicæ Canadensis Inc., 1967
Ce document est protégé par la loi sur le droit d'auteur. L'utilisation des services d'Érudit (y compris la reproduction) est assujettie à sa politique d'utilisation que vous pouvez consulter en ligne.

https://apropos.erudit.org/fr/usagers/politique-dutilisation/ 


\section{Allocution de Son Exc. Mgr Georges Cabana}

- Elle est très impressionnante, la somme des travaux que votre Société canadienne d'Histoire de l'Eglise catholique a compilés depuis 1933. On nous apprend que les rapports de vos congrès annuels, surtout ceux des premières années, sont épuisés et à peu près introuvables. C'est dire la valeur des études que contiennent ces volumes : chaque institution, chaque membre même, tient à en avoir la collection complète.

- Ce qui attire aussi l'attention sur votre Société, c'est que, s'étendant sur tout le pays, elle a tenu ses 33 congrès à divers endroits du Canada, offrant ainsi à chaque région l'occasion d'interroger ses archives et de livrer à toute la nation les leçons de son passé. Il nous fait bien plaisir de noter à ce propos que vous favorisez notre diocèse, puisqu'avec celles de 1940, c'est la deuxième fois que vous tenez vos assises à Sherbrooke.

- Votre mouvement poursuit une auvre louable, parce que vous scrutez le passé non pour le simple plaisir d'en énumérer les faits, mais en vous appliquant à les interpréter, de façon à orienter notre vie pratique, comme le veut le vieil axiome Historia Magistra vito.

- Il y a, en effet, telle chose qui s'appelle la philosophie de l'histoire, et on s'étonne de ce que certains prétendus historiens s'en préoccupent si peu. La consultation et l'enseignement de l'histoire n'ont de vraie valeur que si, dépassant la nomenclature des dynasties ou la chronologie des événements, elles provoquent une méditation salutaire sur le fonctionnement de toute société, sur les relations entre les humains, sur la conduite des individus. Je veux bien, par exemple, que tel chercheur étale savamment les péripéties de la rébellion de 1837, mais il tentera vainement d'enthousiasmer s'il se borne à des éphémérides : il ne m'instruira vraiment et profitablement que s'il mesure l'importance et la portée de cette explosion; que s'il distingue la part de sens commun et l'influence des passions dans les mobiles du soulèvement; que s'il en analyse les causes et en apprécie les conséquences; que s'il en dénoue la trame des circonstances et des affrontements. Il devra même faire des rapprochements avec d'autres insurrections connues, telles celles de Mustapha Kémal, de Cromwell, de Vercingétorix, de Spartacus ... Et s'il en vient à conclure que des causes semblables, dans les mêmes circonstances, ont produit les mêmes effets, à la lumière des constantes il nous persuadera d'user dans l'avenir de mesures plus rationnelles, qui protègent la paix.

* L'historien peut de même être utile notamment à l'Eglise. Cette dernière, tout assistée qu'elle soit par l'Esprit Saint, se compose d'éléments humains qui ont besoin aussi de s'édifier des nobles exemples des prédécesseurs, comme de s'éclairer sur de possibles faux pas : 
l'examen du passé peut encore là inspirer la sainteté, la prudence et la sagesse.

* Ce qui ennoblit l'historien, c'est que sa spécialité l'incite à rechercher la vérité. Le catholique en particulier se doit de rapporter les faits avec une grande loyauté, sans déformation, sans déductions hâtives et sans préjugés. La vérité ne mérite ni d'être enlaidie ni d'être fardée : elle a assez d'éclat pour se défendre d'elle-même. Aussi, nous comprenons bien Léon XIII qui ouvrit toutes grandes aux chercheurs la bibliothèque Vaticane, assuré que l'F.glise sortirait grandie de ses archives séculaires.

* Mesdames, Messieurs, du fait que j'ai accepté de patronner vos journées d'études, vous avez compris que vous étiez les bienvenus dans notre Estrie. A ma joie de vous accueillir s'ajoute un sentiment d'admiration pour tous ceux, organisateurs et conférenciers, qui ont préparé ce congrès enrichissant. Soyez félicités de votre travail. Et comptez que nous serons toujours heureux de vous voir revenir tenir d'autres congrès chez nous. » 